\title{
Prediction of lung function in the inadequately nourished
}

T J Ong, A Mehta, S Ogston, S Mukhopadhyay

\begin{abstract}
Background-In animal models, nutritional deficiency leads to profound qualitative changes in the lung beyond an effect on organ size. Although lung growth is non-isotropic, predictive values for spirometric lung function in children are corrected for height alone. Prediction of lung function should consider isotropic growth and nutritional status concurrently.
\end{abstract}

Aim-To establish whether nutritional status influences lung function following the exclusion of the effect of isotropic growth.

Methods-Nutritional status (weight, body mass index, mid-upper arm circumference, and subscapular and triceps skinfold thicknesses) was assessed, and lung function (forced vital capacity (FVC), forced expiratory volume in one second $\left(F E V_{1}\right)$, and peak expiratory flow rate (PEFR)) was measured in 391 healthy school age children with normal respiratory history and examination in a rural setting in West Bengal, India.

Results-Lung function normalised for sitting height and stature correlated significantly with indices of nutrition in both sexes. Adding weight as an independent variable to sitting height, new reference prediction equations for $\mathrm{FEV}_{1}, \mathrm{FVC}$, and PEFR were calculated.

Conclusions-Nutritional differences influence qualitative aspects of lung development in childhood beyond simple isotropic lung growth. Prediction of lung function must take account of these differences if change as a result of disease is to be accurately measured. The identification and correction of relevant dietary deficiencies might help to improve lung function in children.

(Arch Dis Child 1998;79:18-21)

Keywords: lung development; lung function; nutrition; reference prediction equation

Lung function measured by spirometry (SLF) is an important surrogate measure in the assessment of childhood respiratory status in health and disease. ${ }^{1}$ In order to correct for differences in lung function resulting from growth, SLF in boys or girls is normalised for height. ${ }^{1-3}$ However, the postnatal lung demonstrates non-isotropic growth (whereby the size increment in alveolar dimensions is significantly greater in relation to airway dimensions) and human lung volume correlates directly with body weight. ${ }^{4-6}$ Recent animal models show that relatively severe prenatal and postnatal nutritional deficiency profoundly disturbs lung development, resulting in a major qualitative change beyond an effect on lung size. ${ }^{7-10}$ We hypothesised that similar effects in man lead to diminished lung function in the undernourished child, beyond a simple effect on isotropic growth. Such effects are less likely to manifest in healthy children in the developed world, most of whom are above the international baseline for nutritional status. Hence, we chose a remote rural setting in a developing country for our study.

\section{Methods}

The study took place in Kiarana (in the district of Medinipur, about $100 \mathrm{~km}$ southwest of Calcutta, West Bengal, India) in a completely isolated rural setting with no electricity or piped water, telecommunication, or tarred road/rail links. The inaccessibility of this village results in the total unavailability of standard formula milk, and the study population was breast fed during infancy (lactation failure is usually managed by wet-nursing). Maternal smoking is very rare, and is unlikely to be a confounder, because families spend almost all their waking hours (and frequently sleep) outdoors, except during the short winter period (late November to January), or if it rains; their mud walled houses have open windows and are well ventilated.

Initially, parents of children (aged 4-16 years) attending the village school were given a questionnaire (adapted ATS-DLD-78-C, and translated into Bengali) to exclude subjects with a history of significant respiratory disease. In summary, the questionnaire identified a study population consisting of children with no history of significant cough or sputum production, wheeze, dyspnoea disproportionate to exertion, or acute chest illness (in the six weeks before our study). Of the 810 questionnaires distributed, 623 were returned. One hundred and fifty one of the children were excluded after reviewing the returned questionnaires because of a history of respiratory illness, and the remaining 472 school children attended

Table 1 Age distribution of boys and girls in the study population

\begin{tabular}{|c|c|c|c|c|}
\hline \multirow[b]{2}{*}{ Age (years) } & \multicolumn{2}{|c|}{ Boys $(n=246)$} & \multicolumn{2}{|c|}{ Girls $(n=145)$} \\
\hline & Number & $\%$ & Number & $\%$ \\
\hline $3-5$ & 8 & 3.3 & 3 & 2.1 \\
\hline $6-8$ & 13 & 5.2 & 8 & 5.5 \\
\hline $9-11$ & 61 & 24.6 & 51 & 35.5 \\
\hline $12-14$ & 123 & 49.6 & 61 & 42.1 \\
\hline $15-17$ & 43 & 17.3 & 22 & 15.2 \\
\hline
\end{tabular}


Table 2 Characteristics of the study population

\begin{tabular}{llllll}
\hline & \multicolumn{2}{l}{ Boys $(n=246)$} & & \multicolumn{2}{l}{ Girls $(n=145)$} \\
\cline { 2 - 2 } \cline { 5 - 6 } & Mean $(S D)$ & Centile & & Mean $(S D)$ & Centile \\
\hline Age (years) & $12.3(2.5)$ & & & $11.9(2.5)$ & \\
Stature $(\mathrm{cm})$ & $146.2(14.7)$ & $25(2)$ & & $139.3(11.3)$ & $20(2)$ \\
Sitting height $(\mathrm{cm})$ & $74.5(7.4)$ & $10(1)$ & & $70.9(5.5)$ & $10(1)$ \\
Weight $(\mathrm{kg})$ & $32.4(9.0)$ & $20(5)$ & & $29.5(6.9)$ & $10(2)$ \\
BMI $\left(\mathrm{kg} / \mathrm{m}^{2}\right)$ & $14.8(1.6)$ & $10(1)$ & & $14.9(1.9)$ & $10(2)$ \\
MUAC $(\mathrm{cm})$ & $19.5(2.79)$ & $<<50$ & & $19.4(2.8)$ & $<<50$ \\
SSCF $(\mathrm{cm})$ & $5.6(1.7)$ & $30(6)$ & & $7.5(2.9)$ & $40(7)$ \\
TSF $(\mathrm{cm})$ & $5.00(1.31)$ & $10(3)$ & & $7.09(2.51)$ & $10(3)$ \\
\hline
\end{tabular}

Centiles are compared against a normal, healthy British population. ${ }^{12}$ The reference MUAC data ${ }^{12}$ did not contain a centile distribution.

BMI, body mass index; MUAC, mid-upper arm circumference; SSCF, subscapular skinfold thickness; TSF, triceps skinfold thickness.

clinical respiratory examination, including percussion and auscultation. Eighty one children were found to have signs consistent with upper or lower respiratory tract disease (mainly infection). This strict screening procedure in the selection process minimised the effect of confounding variables (such as lung diseases), and was designed in accordance with established guidelines. ${ }^{11}$

Finally, 391 children (246 boys and 145 girls; see table 1 for age group distribution) were selected for the study, and their respective age, height (sitting and standing), indices of nutritional status (weight, mid-upper arm circumference, and subscapular and triceps skinfold thicknesses), and indices of lung function (forced vital capacity (FVC), forced expiratory volume in one second $\left(\mathrm{FEV}_{1}\right)$, using a portable spirometer, and peak expiratory flow rate (PEFR) were measured for the study population by TJO, in accordance with recommended standards. ${ }^{12}$ Ethical approval and support was provided by Dr B G Panda, senior medical practitioner for the village and president of the school governing board.

The suitability of the lung function data $\left(\mathrm{FEV}_{1}, \mathrm{FVC}\right.$, and PEFR) for $\log _{\mathrm{e}}$ transformation to stabilise variance was verified as described previously. ${ }^{13}$ The association between lung function and nutritional indicators independent of linear growth was analysed after adjustment for sitting height; these isotropic growth corrected variables are denoted with the subscript "c", such as in $\ln \left(\mathrm{FEV}_{1}\right)_{\mathrm{c}}$ and $\ln$ (weight $)_{\mathrm{c}}$. This was achieved by calculating partial correlation coefficients of $\ln$ (lung function) and $\ln$ (nutrition) with sitting height as the controlled variable. Finally, prediction equations were derived from the multiple regression of each index of lung function on $\ln$ (sitting height) and $\ln$ (weight). Statistical analyses were performed on Statistical Package for Social Sciences (SPSS). Unless

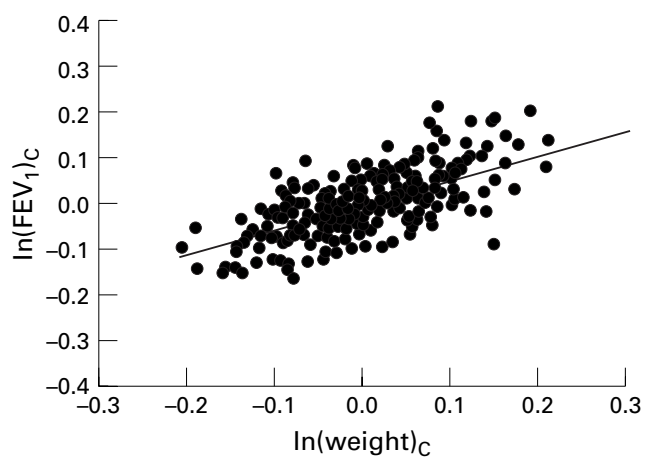

Figure 1 Scattergram of $\ln \left(F E V_{\nu_{c}} v \ln\right.$ (weight) in Indian boys $(n=246)$. The subscript " $c$ " indicates the correction for sitting height of both lung function and nutrition.

stated otherwise, all results are presented as mean (SD) and considered significant when $\mathrm{p}<0.05$. In this paper, stature is defined as standing height.

\section{Results}

Table 2 shows the nutritional status of the study population in relation to healthy British children. Reference data for nutritional status of the local population was not available for comparison. Table 3 shows the partial correlation coefficients of linear regression analyses between indices of lung function and nutrition, after correction for sitting height (similar results were obtained for stature normalisation, except the $R$ values were lower). The scattergram in fig $\left.1\left(\ln \left(\mathrm{FEV}_{1}\right)_{c} v \ln \text { (weight) }\right)_{c}\right)$ is an illustration of how the data summarised in table 3 was derived, and the subscript "c" denotes correction for sitting height. Weight is the only variable that shows significant correlation with all lung function parameters in both boys and girls, independent of isotropic growth. The multiple regression of $\ln \left(\mathrm{FEV}_{1}\right)$ against $\ln$ (weight) and $\ln$ (sitting height) results in significant reduction $(\mathrm{p}<0.001)$ in variability, when compared with $\ln \left(\mathrm{FEV}_{1}\right)$ against $\ln$ (sitting height) or $\ln$ (stature) alone. Similar outcomes were obtained for $\ln (\mathrm{FVC})$ and $\ln ($ PEFR $)$ in both boys and girls. However, the inclusion of additional variables did not lead to significant improvement in variability $(p>0.05)$. Thus, the derivation of prediction equations for SLF incorporated transformed data of weight and sitting height (table 3 ). Both residuals and antilog of the residuals exhibited consistent normal distributions without skewing; table 4 shows the means and standard deviations of the antilogged residuals, which are the ratios of actual to predicted lung

Table 3 Partial correlation coefficients of linear regression analyses between indices of lung function and nutrition after correction for sitting height (denoted by subscript "c")

\begin{tabular}{|c|c|c|c|c|c|c|}
\hline & \multicolumn{3}{|c|}{ Boys $(n=246)$} & \multicolumn{3}{|c|}{ Girls $(n=145)$} \\
\hline & $\ln \left(F E V_{\nu_{c}}\right.$ & $\ln (F V C)_{c}$ & $\ln (P E F R)_{c}$ & $\ln \left(F E V_{\nu}\right)_{c}$ & $\ln (F V C)_{c}$ & $\ln (\text { PEFR })_{c}$ \\
\hline $\ln$ (weight) & $0.45^{\star}$ & $0.44^{\star}$ & $0.38^{\star}$ & $0.45^{\star}$ & $0.45^{\star}$ & $0.17^{\star}$ \\
\hline $\ln (\mathrm{BMI})_{\mathrm{c}}$ & $0.25^{\star}$ & $0.25^{\star}$ & $0.17^{\star}$ & $0.25^{\star}$ & $0.24^{\star}$ & $0.06 \dagger$ \\
\hline $\ln (\mathrm{MUAC})_{\mathrm{c}}$ & $0.18^{\star}$ & $0.20^{\star}$ & $0.18^{\star}$ & $0.21^{\star}$ & $0.21^{\star}$ & $0.02 \dagger$ \\
\hline $\ln (\mathrm{SSCF})_{\mathrm{c}}$ & $0.05 \dagger$ & $0.06 \dagger$ & $0.11 \dagger$ & $0.22^{\star}$ & $0.18^{\star}$ & $0.13 \dagger$ \\
\hline $\ln (\mathrm{TSF})_{\mathrm{c}}$ & $0.05 \dagger$ & $0.07 \dagger$ & $0.01 \dagger$ & $0.18^{\star}$ & $0.15 \dagger$ & $0.08 \dagger$ \\
\hline
\end{tabular}

${ }^{\star} \mathrm{p}<0.05 ; \nmid \mathrm{p}>0.05$.

BMI, body mass index; MUAC, mid-upper arm circumference; SSCF, subscapular skinfold thickness; TSF, triceps skinfold thickness. 
Table 4 Proposed multiple regression equations of ln (lung function) on $\ln ($ sitting height) and ln (weight) in undernourished children in a rural population of West Bengal, India

\begin{tabular}{|c|c|c|c|c|c|c|}
\hline \multirow[b]{2}{*}{$\begin{array}{l}\text { Dependent } \\
\text { variable }\end{array}$} & \multicolumn{3}{|c|}{ Regression coefficients } & \multirow{2}{*}{$\begin{array}{l}\text { Multiple } \\
\text { correlation } \\
\text { coefficient }\left(R^{2}\right)\end{array}$} & \multicolumn{2}{|c|}{$\begin{array}{l}\text { Distribution of } \\
\exp (\text { residual })^{\star}\end{array}$} \\
\hline & $\begin{array}{l}\text { ln (sitting } \\
\text { height) }\end{array}$ & $\ln$ (weight) & Intercept & & Mean & $S D$ \\
\hline \multicolumn{7}{|l|}{ Boys $(n=246)$} \\
\hline $\ln \left(\mathrm{FEV}_{1}\right)$ & 1.080 & 0.657 & -6.261 & 0.870 & 1.004 & 0.110 \\
\hline $\ln (\mathrm{FVC})$ & 1.000 & 0.669 & -5.918 & 0.857 & 1.004 & 0.120 \\
\hline $\ln (\mathrm{PEFR})$ & 0.781 & 0.614 & 0.378 & 0.787 & 1.010 & 0.140 \\
\hline \multicolumn{7}{|l|}{ Girls $(n=145)$} \\
\hline $\ln \left(\mathrm{FEV}_{1}\right)$ & 1.268 & 0.518 & -6.667 & 0.780 & 1.009 & 0.120 \\
\hline $\ln (\mathrm{FVC})$ & 1.233 & 0.527 & -6.529 & 0.781 & 1.005 & 0.120 \\
\hline $\ln$ (PEFR) & 1.545 & 0.338 & -2.093 & 0.416 & 0.990 & 0.130 \\
\hline
\end{tabular}

*Actual lung function $\div$ predicted lung function.

function values. This information can be used to calculate SLF standard deviation scores or centile positions for individual children. ${ }^{14}$

\section{Discussion}

By demonstrating that lung function normalised for isotropic growth correlates strongly with indices of nutrition in both sexes, we present supportive data from human subjects consistent with the hypothesis, recently generated from animal models, that nutritional deficiency profoundly affects qualitative aspects of lung development in early life, ${ }^{7-10}$ beyond simple changes in organ size. It follows that a malnourished child with lung function significantly below the predicted value (by current clinical models using stature alone) could be diagnosed incorrectly as suffering from serious respiratory disease when the problem is related to nutrition. In the absence of respiratory disease, a typical malnourished boy's "percentage of predicted $\mathrm{FEV}_{1}$ " would be $73.3 \%$ when calculated from British clinical reference values, and $85.5 \%$ when using the equation for stature alone derived from our study (appendix). However, with the incorporation of weight and sitting height in our proposed prediction equation for $\mathrm{FEV}_{1}$, his computed score would have been $94.3 \%$. Recent findings of Stein et al demonstrate that fetal undernutrition in utero results in changes in lung structure, which in turn lead to chronic airflow obstruction ${ }^{15}$; it would be interesting, therefore, to investigate whether improved nutrition in early life could enhance lung function prospectively. Because

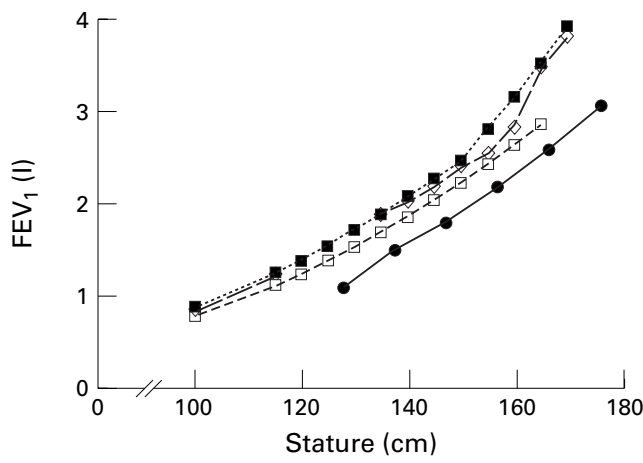

Figure 2 Predicted FEV (forced expiratory volume in one second) data of British white (open diamonds), ${ }^{21}$ Singaporean Chinese (closed squares), ${ }^{2}$ and Malaysian Chinese (open squares) ${ }^{22}$ children and data from our study of rural Indian children (derived using stature alone; closed circles). our study was not designed to define the mechanism(s) of impaired lung function in malnutrition, we cannot exclude the possibility that malnutrition causes concomitant respiratory muscle weakness, which in turn may cause impaired effort.

In deriving our SLF prediction equations, we chose sitting height over stature as the independent variable because the former reflects lung length more accurately, by removing the effects of any disproportionate growth of trunk to leg. ${ }^{16}$ Our data (not shown) confirmed that sitting height, when compared with stature, also correlated better with lung function and weight; this corroborates with the results of Schrader et al. ${ }^{17}$ Similar findings favouring the use of sitting height as the predictor variable were reported by Miller et $a l .{ }^{18}$ The addition of nutritional indices to SLF prediction equations was proposed previously by Cotes and colleagues, whose results showed that the use of fat free mass (or more conveniently, body mass), increased the accuracy of SLF prediction. ${ }^{19}$ However, subsequent findings by Kristufek et al using a mathematical construct, indicated that the variable "mass" contributed negligibly in SLF prediction equations in an optimally nourished population. ${ }^{20}$ Our findings demonstrate that in the malnourished population, nutritional status definitely influences lung function independent of isotropic growth, and weight represents an important and convenient surrogate marker of nutritional state. Therefore, prediction of lung function in an undernourished child must take into account weight and sitting height, if change as a result of pulmonary disease is to be assessed accurately. The equations presented in this paper achieve this purpose.

SLF performance varies between apparently "healthy, well nourished" ethnic groups and, so far, the reported differences have been attributed to anthropological factors; consequently, reference predicted values and equations have been proposed for each group. ${ }^{2122}$ To explore the hypothesis that other underlying factors could explain this variation, we have merged data from three studies and of our own to enable us to draw fig 2. It is interesting to note that SLF from Singaporean Chinese children are very similar to the data from white children in Britain, but at least $10 \%$ higher than their Malaysian Chinese counterparts at every point on the plot; in addition, lung function data from our study population of Indian children is considerably lower. Because Singaporean Chinese and Malaysian Chinese children are ethnically similar, the observed differences in SLF between races cannot be explained on the basis of ethnic anthropometric attributes alone. The per capita Gross Domestic Product (GDP) for Singapore, Great Britain, Malaysia, and India are: US\$21 493, US\$18 138, US $\$ 8763$, and US $\$ 1280$, respectively, and the corresponding average daily calorie intake for each person is $3198,3149,2774$, and $2243 .^{23}$ Thus, a lower per capita GDP is associated with reduced daily calorie intake and with diminished lung function. Based on these observations, we think that it is important to 
examine the following hypotheses: (1) nutritional differences account for variations in SLF between different ethnic groups in the world, and (2) a predictive equation for lung function that accounts for nutritional status beyond isotropic growth is universally valid (that is, for all ethnic groups). We hope that our work will facilitate future international collaboration aiming to address these important issues.

We thank Dr B Panda (Mobar, Calcutta), physician, philanthropist, and president of the governing board of Moyna Shikshya$\tan$ (the school) for the organisation of this project, and the participating children, parents, teachers, and administrators of Kiarana village for their cooperation. This work was sponsored by the Commonwealth Foundation, Chest, Heart and Stroke Found tion, British Medical and Dental Students' Trust, and Pharmacia; TJO was a Rogers Fund scholar with the Medical Research Council (UK)

\section{Appendix}

The calculation of "percentage of predicted $\mathrm{FEV}_{1}$ " of a 12 year old boy with a stature of $146 \mathrm{~cm}$, sitting height of $74.5 \mathrm{~cm}$, weight of $27 \mathrm{~kg}$, and $\mathrm{FEV}_{1}$ of 1.65 litres is as follows:

Predicted $\mathrm{FEV}_{1}$ from white clinical reference data (using stature alone) $)^{21}=2.25$ litres

Percentage of predicted $=(1.65 \div 2.25)$

$\star 100=73.3 \%$

Predicted $\mathrm{FEV}_{1}$ using the our study's equation for stature $=\exp \left(2.83^{\star} \ln (146)-13.43\right)=$ 1.93 litres

Percentage of predicted $=(1.65 \div 1.93)$ $\star 100=85.5 \%$

Predicted $\mathrm{FEV}_{1}$ from our study's proposed equation (for sitting height and weight) $=\exp$ $\left(1.08^{\star} \ln (74.5)+0.657^{\star} \ln (27)-6.261\right)=1.75$ litres

Percentage of predicted $=(1.65 \div 1.75)$

$\star 100=94.3 \%$

Reference data from the British population was chosen for comparison because it is still widely used by clinicians in the UK and in India when assessing lung function in children. A previously published prediction equation of lung function in West Bengal children was derived from non-representative sedentary, middle class, urban children. ${ }^{24}$

1 Cotes JE. Lung function: assessment and application in medicine. Oxford: Blackwell Scientific, 1993.
2 Connett GJ, Quak SH, Wong ML, et al. Lung function reference values in Singaporean children aged $6-18$ years. Thorax 1994;49:901-5.

3 Godfrey S, Kamburoff PL, Nairn JR. Spirometry lung volumes and airway resistance in normal children aged 5-18 years. Br F Dis Chest 1970;64:15-24.

4 Zeltner TB, Burri PH. The postnatal development and growth of the human lung. II. Morphology. Resp Physiol $1987 ; 67: 269-82$

5 Massaro GD, Massaro D. Postnatal lung growth-evidence that the gas-exchange region grows fastest at the periphery. Am f Physiol 1993;265:L319-22.

6 Silverman M. Respiratory disorders. In: Campbell AGM, McIntosh N, eds. Forfar and Arneil's textbook of paediatrics, 4th ed. Edinburgh: Churchill Livingston, 1992.

7 Lechner AJ. Perinatal age determines the severity of retarded lung development induced by starvation. Am Rev Resp Dis 1985;131:638-43.

8 Gaultier C. Malnutrition and lung growth. Pediatr Pulmonol 1991;10:278-86.

9 Riley DJ, Thakkervaria S. Effect of diet on lung structure, connective tissue metabolism and gene expression. $\mathrm{F}$ Nutr 1995;125:S1657-60

10 Zhang HJ, German BJ. Dietary modulation of phospholipid fatty acid composition and lipoxygenase products in mouse lung homogenates. Lipids 1996;31:19-25.

11 Ferris BG Jr. Epidemiology standardisation project. Am Rev Resp Dis 1978;118:7-53.

12 American Thoracic Society. Standardisation of spirometry1987 update. Am Rev Resp Dis 1987;136:1285-98.

13 Buckler J. A longitudinal study of adolescent growth. London: Springer-Verlag, 1990

14 Chinn S, Rona RJ. Height and age adjustment for cross-sectional studies of lung function in children aged 6-11 years. Thorax 1992;47:707-14.

15 Stein CE, Kumaran K, Fall CHD, et al. Relation of fetal growth to adult lung function in South India. Thorax 1997; 52:895-9.

16 Simon G, Reid L, Tanner JM, et al. Growth of radiologially determined heart diameter, lung width, and lung length from 5-19 years, with standards for clinical use. Arch Dis Child 1972;47:373-81.

17 Schrader PC, Quanjer PH, van Zomeren BC, et al. Changes in the $\mathrm{FEV}$-height relationship during pubertal growth. Bull Eur Pysiopathol Resp 1984;20:381-8.

18 Miller GJ, Saunders MJ, Gilson RJC, et al. Lung function in healthy boys and girls in Jamaica in relation to ethnic composition, test exercise performance, and habitual physical activity. Thorax 1977;32:486-96.

19 Cotes JE, Dabbs JM, Hall AM, et al. Sitting height, fat-free mass and body fat as reference variables for lung function in healthy British children: comparison with stature. Ann Hum Biol 1979;6:307-31.

20 Kristufek P, Brezina M, Ciutti P, et al. Reference values and modelling of lung function development as a transcendent function of age, body and height and mass. Bull Eur Physiopathol Resp 1987;23:139-47.

21 Rosenthal M, Bain SL, Cramer D, et al. Lung function in white children aged 4 to 19 years: I-spirometry. Thorax 1993;48:794-802.

22 Azizi BHO, Henry RL. Ethnic differences in normal spirometric lung function of Malaysian children. Resp Med 1994;88:349-56.

23 Asiaweek 1995;21(31):63-4.

24 Chatterjee S, Mandal A. Pulmonary function studies in healthy school boys of West Bengal. Fap f Physiol 1991;41: $797-808$. 